\title{
Respiratory syncytial virus. Clinical and epidemiological pattern in pediatric patients admitted to a children's hospital between 2000 and 2013
}

\author{
María Florencia Lucion, M.D. ${ }^{a}$, María del Valle Juárez, M.D. ${ }^{a}$, Mariana Viegas, M.D. ${ }^{b}$, \\ Vanesa Castellano, M.D. ${ }^{a}$, Viviana Sandra Romanin, M.D. ${ }^{a}$, Marcela Grobaporto, M.D. ${ }^{a}$, \\ Julia Bakir, M.D. ${ }^{a}$, Alicia Susana Mistchenko, M.D. ${ }^{b}$, and Ángela Gentile, M.D. ${ }^{a}$
}

\begin{abstract}
Introduction. Respiratory syncytial virus (RSV) is the major causative organism associated with acute lower respiratory tract infections in children.The objective of this study was to describe the clinical and epidemiological pattern of RSV and identify risk factors for RSV infection. Population and Methods. Prospective, cohort study on patients hospitalized due to acute lower respiratory tract infection at Hospital de Niños RicardoGutiérrez between March and November throughout the 2000-2013 period. The virological diagnosis of RSV, adenovirus, influenza and parainfluenza was performed by indirect immunofluorescence using nasopharyngeal aspirates.
\end{abstract}

Results. A total of 12555 children were included, $38.2 \%$ (4798) had virus rescued from samples. RSV accounted for $81.8 \%$ of cases $(3924 / 4798)$ with no significant annual variations (71.288.1) and with an epidemic seasonal pattern (May through July); RSV was followed by influenza $(7.6 \%)$, parainfluenza $(5.9 \%)$, and adenovirus $(4.7 \%)$. The median age of patients with RSV rescue (3924) was 7 months old (0214 months old), while $74.2 \%$ were younger than 1 year old, $43.1 \%$ were younger than 6 months old, $56.5 \%$ were males and the most common clinical presentation was bronchiolitis $(60.7 \%)$. Comorbidities were observed in $41.6 \%$ of cases. The most common comorbidities were chronic respiratory disease $(74 \%)$, congenital heart disease $(14 \%)$, and chronic neurological disease (10.2\%).Complications occurred in $25 \%$ of cases. The case fatality rate was $1.9 \%(74 / 3888)$. Independent predictors of RSV infection were age $<3$ months old (OR: 2.8 [2.14-3.67], $p<0.01$ ), clinical presentation of bronchiolitis (OR: 1.54 [1.32-1.79], $p<0.01)$, and hypoxemia at the time of admission (OR: 1.84 [1.42-2.37], $p<0.01$ ). Conclusions. RSV infection displayed a seasonal pattern and was associated with infants younger than 3 months old with bronchiolitis and hypoxemia at the time of admission.

Key words: respiratory syncytial virus, bronchiolitis, epidemiology.

http:/ /dx.doi.org/10.5546/aap.2014.eng.397

\section{INTRODUCTION}

Acute lower respiratory tract infections (ALRTIs)in children are one of the most common reasons for medical consultation, school absenteeism, hospitalizations and child mortality. ${ }^{1,2}$ Mortality is higher in developing countries in comparison with developed countries, especially in children younger than 5 years old. ${ }^{3}$

In Argentina, according to the latest report by the Ministry of Health (December 2012), respiratory diseases were the third cause of mortality in children younger than 5 years old (after perinatal conditions and congenital anomalies) and accounted for $6.3 \%$ (572/9037) of all deaths for a definite cause in this age group in 2012. ${ }^{4}$

Viruses are the most common pathogens involved in ALRTIs, as shown in several national and international publications. ${ }^{1-5}$

The recommended rapid diagnostic method for the detection of respiratory viruses is usually indirect immunofluorescence (IIF). This has been a widely used technique due to its swiftness, low cost, simplicity, adequate specificity and sensitivity. IIF allows to identify viral agents generally related to ALRTIs, such as respiratory syncytial virus (RSV), influenza, parainfluenza, and

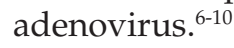

The rapid identification of viral etiologic agents is essential for the epidemiological monitoring of this condition, it helps to reduce the unnecessary use of antibiotics and, as a result, decreases bacterial resistance, therefore improving the care provided to hospitalized patients and optimizing available resources. In addition, it enables to adopt measures 
aimed at reducing nosocomial transmission by implementing contact or respiratory isolation measures as appropriate.

Although in the past years, a large number of studies have been conducted to assess molecular techniques for the diagnosis of respiratory virus, IIF is still the technique of choice in the case of RSV, the object of this study, due to its high sensitivity and specificity, which is not the case with other respiratory viruses (adenovirus). Detection sensitivity through molecular techniques has increased between $4 \%$ and $7 \% .{ }^{10}$ Even in the "PCR era", IIF is a method especially adapted for the ongoing surveillance for local epidemiology of respiratory viruses in the pediatric population. ${ }^{9}$

Particularly, RSV is the major pathogen causing bronchiolitis and pneumonia in young infants, and different epidemiological studies have shown that the primary RSV infection takes place between 6 weeks of age and 2 years old. ${ }^{2,11-17}$

Given the magnitude of the problem caused by ALRTIs, it is important to describe their clinical and epidemiological pattern and the burden of RSV in our setting and identify risk factors for RSV infection. In the future, this information would allow to have data to work on the prevention of RSV infection with specific vaccines and optimize administration schedules and ages, and then evaluate their effectiveness and adjust health policies accordingly. ${ }^{18}$

The objective of this study was to describe the clinical and epidemiological pattern of RSV and identify risk factors for RSV infection.

\section{POPULATION AND METHODS}

This was an analytical, epidemiological, and prospective cohort study. All patients hospitalized due to ALRTIs, detected through the Epidemiological Surveillance Program (PVE, Programa de Vigilancia Epidemiológica) for ALRTIs of Hospital de Niños RicardoGutiérrez between March and November throughout the 20002013 period (14 years) were included. Patients with ALRTI with RSV rescue confirmed to have been hospital-acquired were excluded.

The Epidemiological Surveillance Program conducts an active surveillance of patients hospitalized due to ALRTIs (first-time or recurrent episodes of bronchial obstruction in infants younger than 2 years old and pneumonias in any age group). In our study, patients hospitalized due to ALRTIs with RSV rescue were included. Data were collected in an epidemiological card, including date of admission, demographic data, age, sex, origin, clinical presentation (bronchiolitis, pneumonia), prior hospitalizations related to a respiratory condition, readmissions due to a recurrent episode, comorbidities, presence of household members with probable viral acute respiratory disease (rhinorrhea, cough and/or fever) or close contact with such condition, perinatal history, complications during hospitalization, clinical course (discharge, transfer to a different facility, death), treatment, and length of stay.Comorbidities were defined as chronic or recurrent respiratory disease, malnutrition, congenital heart disease, genetic condition, neurological disease, and immunosuppression. The presence of any of the following conditions was recorded as chronic or recurrent respiratory disease:recurrent obstructive bronchitis (ROB) or asthma, gastroesophageal reflux, cystic fibrosis of the pancreas, bronchopulmonary dysplasia, recurrent pneumonia, and recurrent laryngitis. $\mathrm{ROB}$ was defined as the occurrence of two or more bronchoobstructive episodes. The following were recorded as complications: otitis, pneumothorax, persistent atelectasis, sepsis, respiratory failure, and nosocomial infection. Nosocomial infection was defined as an acute exacerbation of the respiratory condition, manifested as fever, increased oxygen requirement, or changes in the radiological pattern, present in included patients as of 48 hours of hospitalization and that was absent at the time of admission.

\section{Diagnostic Methods}

The clinical or radiological diagnosis of bronchiolitis and pneumonia was performed in compliance with the Guidelines of the Sociedad Argentina de Pediatría. ${ }^{1}$ The virological diagnosis was performed through IIF using nasopharyngeal aspirates collected in the first 24 hours of hospitalization. Samples were obtained using a K-30 nasogastric tube introduced through the nose and submitted immediately to the hospital's Laboratory of Virology.For antigen detection in aspirate cells, the IIF rapid diagnostic method was used. Samples were washed in buffer saline solutionand cells were separated by centrifugation and then placed on a microscope slide and fixed with acetone. The following respiratory viruses were looked for: RSV, adenovirus, influenza A and B, and parainfluenza 1, 2 and 3 with monoclonal antibodies (Chemicon, USA). Immunofluorescence was revealed with the corresponding anti-species sera. 
For genotyping, the ectodomain of the RSV $G$ glycoprotein was sequenced because it is one of the main surface glycoproteins that lead to the development of neutralizing antibodies. Nucleic acids were extracted directly from nasopharyngeal aspirates using the NucleoSpin ${ }^{\circledR}$ RNA/Protein (Machery-Nagel) kit following the manufacturer's instructions. RNA was then retrotranscribed and amplified using the Qiagen-OneStep RT-PCR (Qiagen) kit following the manufacturer's instructions and using the primers specified for the above mentioned region. Subsequently, a bidirectional sequencing was performed on PCR purified products using the BigDye Terminator v3.1 (Applied Biosystems) kit in the ABI3500 genetic analyzer (Applied Biosystems).

\section{Data Analysis}

The statistical analysis was done using the Epi Info software version 7 (CDC, Atlanta, USA). Qualitative outcome measures were analyzed using Yates corrected $c^{2}$ test. The relative risk (RR) was considered the measure of association, with a $95 \%$ confidence interval (CI). A multivariate analysis was conducted to establish independent predictors, using the logistic regression model of the SPSS software version 15.0 for qualitative outcome measures. A value of $p<0.05$ was considered significant.

\section{RESULTS}

A total of 12555 children were included, 38.2\% (4798) had some virus rescued from samples. This is the population to be analyzed in the study.

RSV accounted for $81.8 \%$ (3924/4798) of positive samples. A very low incidence was observed for the rest of the identified viruses: influenza accounted for $7.6 \%(365 / 4798)$ of cases, parainfluenza, 5.9\% (282/4798), and adenovirus, $4.7 \%(227 / 4798)$. The annual distribution of ALRTIs due to RSV was 2000: $84.8 \%$; 2001: $71.2 \%$; 2002: 79.8\%; 2003: 74.7\%; 2004: 87.4\%; 2005: 84.4\%; 2006: 88.1\%; 2007: 78.0\%; 2008: 81.2\%; 2009: 77.6\%; 2010: 87.3\%; 2011: 82.8\%; 2012: 84.7\%; 2013: 71.5\% (peak May through July) (Figure 1). In 2009, during the H1N1 influenza A virus pandemic, RSV was displaced by this pandemic virus throughout the highest circulation period.

The highest incidence of ALRTIs due to RSV was predominant between epidemiological weeks (EW) 25 and 30 (June-July), except in 2010 and 2012, when peaks presenting as earlier as EW 18 (May) (Figure 2). The annual hospital incidence rate for bronchiolitis was 39.1/1000 (2003 peak: $47.8 / 1000)$, while for bronchiolitis due to RSV, it was 15.4/1000 (8-19.4) with a seasonal epidemic pattern (May through July).

The median age of patients hospitalized with a diagnosis of ALRTI due to RSV was 7 months old (0-216 months old). Of them, $10 \%$ were younger

FIGURE 1. Annual distribution of respiratory viruses in children hospitalized due to acute lower respiratory tract infection at Hospital de Niños R. Gutiérrez," 2000-2013

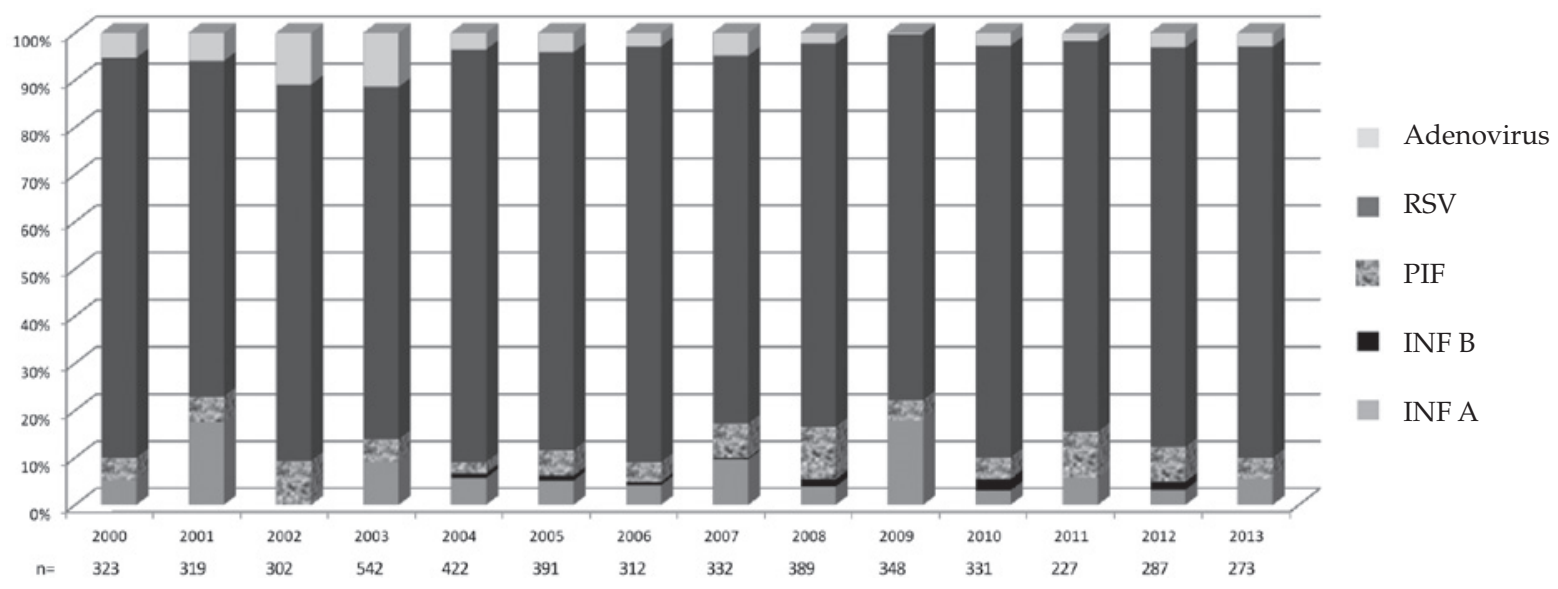

RSV: respiratory syncytial virus. PIF: parainfluenza. INF B: influenza B. INF A: influenza A. 
than 2 months old, $43.1 \%$ were younger than 6 months old, and $74.2 \%$ were younger than 1 year old; $56.5 \%$ were males. The most common clinical presentation was bronchiolitis, with $60.7 \%$ of cases, while the other $39.3 \%$ corresponded to pneumonia. Forty-eight percent of patients had a history of intrafamilial contact or close contact with acutely-ill individuals.

Readmissions due to the same event corresponded to $3.2 \%$ of cases, while prior hospitalizations for a respiratory condition corresponded to $26.9 \%$. Of these patients, $41.6 \%$ had concomitant pathologies. The most common were chronic respiratory disease (CRD) (74\%), congenital heart disease $(14 \%)$, prematurity $(13.6 \%)$, chronic neurological disease $(10.2 \%)$, malnutrition $(5.1 \%)$, and immunosuppression $(1.9 \%)$. Recurrent obstructive bronchitis accounted for $94 \%$ of all recorded CRDs (Table 1).

The median hospital length of stay was 7 days (1-200 days). Complications during hospitalization occurred in $25 \%$ of cases (Table 2 ). Intensive care with mechanical ventilation due to respiratory failure was required in $6.9 \%$ of patients. Nosocomial infections were present in $6.6 \%$ of patients. The case fatality rate was $1.9 \%$ (74/3888).

Risk factors associated with RSV infection compared to other viruses were age younger than 3 months old, clinical presentation of bronchiolitis, and hypoxemia at the time of admission (Table 3).

The analysis of genotypic characteristics of RSV strains in hospitalized patients during the study period (2000-2012) disclosed two RSV subtypes,A and B, which have circulated concurrently in the pediatric population. Subtype A was observed every year included in the analysis period, except in 2005, when only subtype B was found in analyzed samples. However, subtype A was the only one identified in 2000. Genotypic characteristics of subtype B showed genotype BA with a duplication of 20 amino acids in $\mathrm{G}$ glycoprotein in relation to the reference strain of RSV, B/CH18537/63,

TABLE 1. Chronic respiratory disease, distribution by pathology

\begin{tabular}{lcc}
\hline Chronic respiratory disease $(\mathbf{n = 1 2 0 4})$ & & \\
\hline Recurrent obstructive bronchitis - & $\mathbf{n}$ & $\mathbf{\%}$ \\
Asthma & 1115 & 94 \\
Recurrent pneumonia & 31 & 2.6 \\
Gastroesophageal reflux & 18 & 1.5 \\
Bronchopulmonary dysplasia & 13 & 1.2 \\
Cystic fibrosis of the pancreas & 5 & 0.4 \\
Recurrent laryngitis & 4 & 0.3 \\
\hline
\end{tabular}

FIGURE 2. Temporal series of respiratory syncytial virus cases in children hospitalized due to acute lower respiratory tract infection at Hospital de Niños R. Gutiérrez, 2000-2013

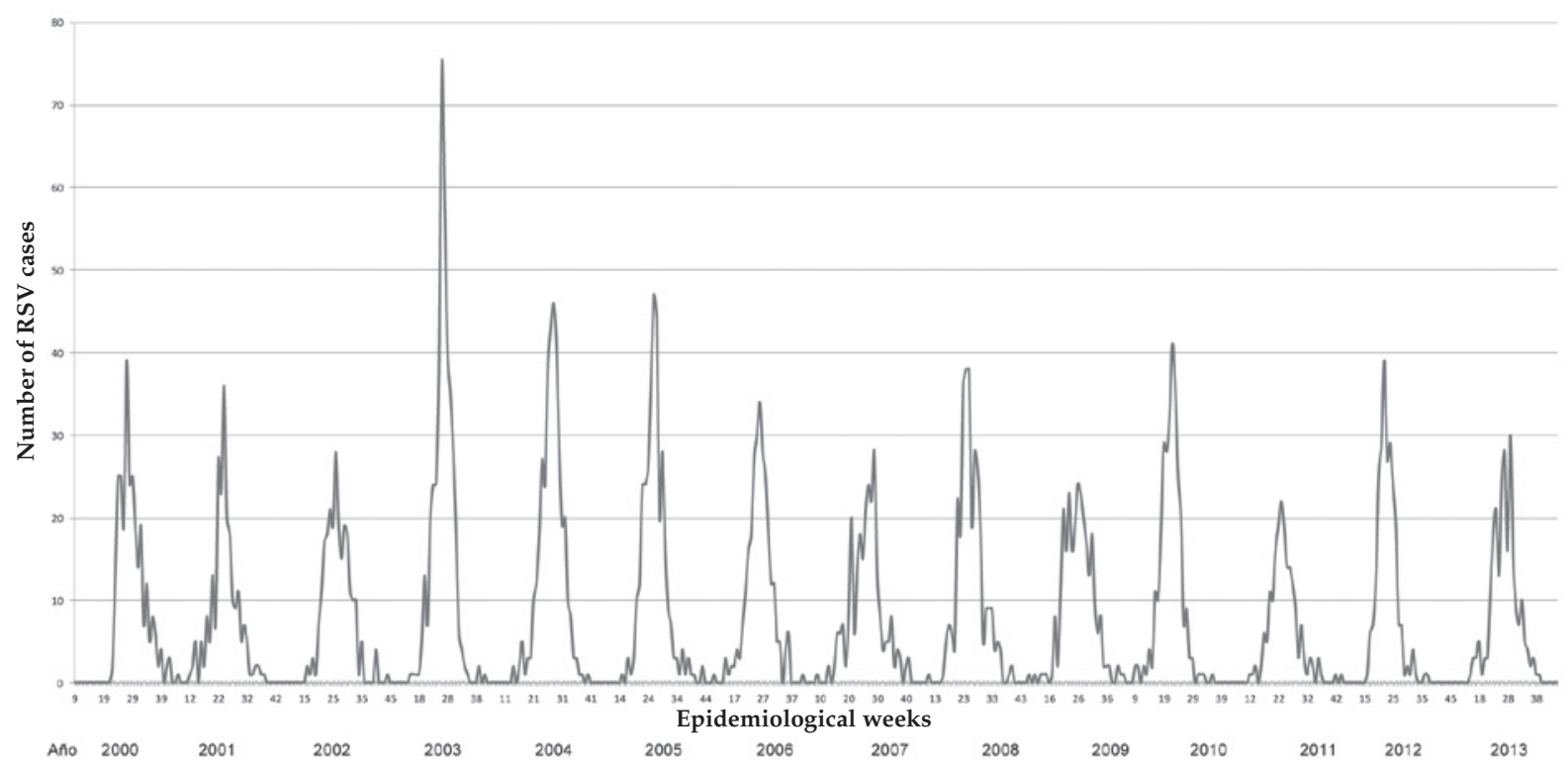


first described inBuenos Aires in 1999, was the most commonly observed genotype within this subtype in the studied population. ${ }^{19,20}$ With regard to genotypes identified in subtype A, GA2 and GA5 were observed to circulate concurrently, particularly in the 2000-2008 period, while a new genotype emerged in 2009, called NA1, which was highly related to GA2 and finally displaced it in the subsequent years. It is worth noting that in 2012, a subtype A strain of RSV started

TABLE 2. Complications during hospitalization, distribution by pathology

\begin{tabular}{lcc}
\multicolumn{1}{l}{ Complications during hospitalization } & $(\mathbf{n = 1 2 0 8})$ & \\
$\mathbf{n}$ & $\mathbf{\%}$ \\
\hline Acute otitis media & 300 & 24.8 \\
Respiratory failure & 302 & 25.0 \\
Nosocomial infection & 243 & 20.1 \\
Persistent atelectasis & 174 & 14.4 \\
Sepsis & 133 & 11.0 \\
Pneumothorax & 44 & 3.6 \\
Effusion & 12 & 1.0 \\
Total number of complications & 1208 & 100.0 \\
\hline
\end{tabular}

TABLE 3. Analysis of risk factors associated with respiratory syncytial virus infection

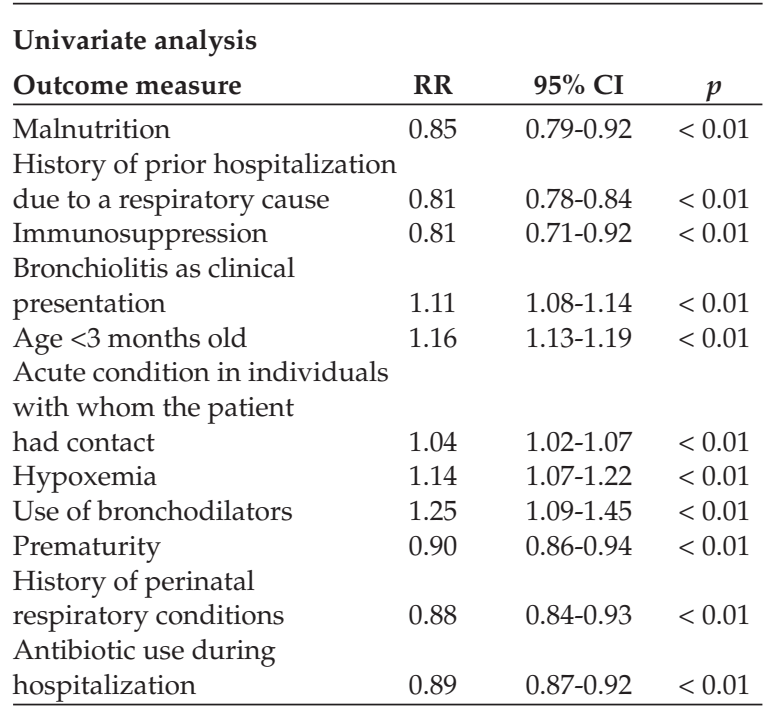

Multivariate analysis

\begin{tabular}{lccc} 
Outcome measure & OR & IC 95\% & $p$ \\
\hline Bronchiolitis as clinical & & & \\
presentation & 1.54 & $1.32-1.79$ & $<0.01$ \\
Age $<3$ months old & 2.80 & $2.14-3.67$ & $<0.01$ \\
Hypoxemia & 1.84 & $1.42-2.37$ & $<0.01$ \\
\hline
\end{tabular}

circulating in our region, which had a duplication of 24 amino acids in G glycoprotein, and was called genotype ON1.

\section{DISCUSSION}

ALRTIs are an important cause of morbidity and mortality, medical consultations and hospitalizations in the first years of life.

RSV was the viral agent most commonly identified in our population as the cause of ALRTIs. This finding is consistent with data published in the international literature. ${ }^{21-25}$ During the 14-year period of our study, RSV was predominant over other circulating viruses, even in 2009, year of the H1N1 influenza A pandemic. Although RSV was displaced during the peak circulation of H1N1 that year, the total number of ALRTIs due to RSV was higher than the total number of H1N1 cases.

The analysis of the genotypic characteristics of RSV strains indicates that it is likely that the virus' plasticity allows it to adapt to such drastic changes on its surface proteins, granting it evolutionary advantages that allow it to undermine the previously generated immune response; this way, RSV is able to circulate in the pediatric population and continue to be the most commonly observed viral agent in infants younger than 1 year old with ALRTIs.

In mild climate regions, RSV is markedly seasonal and characterized by the occurrence of an annual outbreak during months of the lowest temperature. We clearly and objectively identified RSV seasonality, predominant between May and July and with annual differences in terms of magnitude and time of onset of the outbreak.

Differences in relation to the magnitude of annual RSV outbreaks have been observed, which led to describing RSV as having "biannual cycles," with early major outbreaks alternating with later minor ones. ${ }^{1}$

Such biannual cyclic pattern was first described in Europe; in our 14-year study, this alternation was corroborated in the past five years, similar to what has been described by different studies. ${ }^{26,27}$ The value of these data is still limited, but if cycles were confirmed to be regular, data would become vitally significant for planning health actions. ${ }^{1}$

The largest RSV outbreak occurred in 2003, although major outbreaks were also observed in 2010 and 2012 with an early onset, alternating with outbreaks of lesser magnitude and later onset in other years. 
According to data collected on the annual hospital incidence rate of bronchiolitis at our site, $41 \%$ of cases were caused by RSV, consistent with several studies conducted in children younger than 5 years old hospitalized due to ALRTIs. ${ }^{1}$ Bronchiolitis as the most common clinical presentation was predominant in infants aged 6 to 9 months old, with an incidence peak between 2 and 7 months old; these findings have also been described by international studies. ${ }^{28-30}$ In our series, $60.7 \%$ of infants had bronchiolitis at the time of admission, while the remaining $39.3 \%$ had pneumonia. It should be noted that viruses account for the most common cause of community-acquired pneumonia, especially in children younger than 2 years old. ${ }^{1,2}$

The population considered to be at a high risk is made up of children with chronic pulmonary disease, congenital heart disease, and prematurity, all of whom have a higher risk of hospitalization than the general population.In agreement with our results, it has been observed that $41.5 \%$ of children hospitalized with ALRTIs due to RSV had underlying conditions. The most common underlying conditions included chronic respiratory disease, congenital heart disease, prematurity, chronic neurological disease, malnutrition and immunosuppression. ${ }^{11}$ These data may be magnified because our hospital is a national referral center where help is sought for children with these conditions, and this may be considered one of the weaknesses of our study.

A fourth of our population had some complication, being acute otitis media (24.8\%) and atelectasis $(14.4 \%)$ the most common ones. International studies have estimated that RSV is the main virus associated with acute otitis media in children ${ }^{31}$ and that a mixed viral-bacterial infection in the middle ear could worsen the course of such condition. ${ }^{32}$

The case fatality rate for RSV in infants younger than 1 year old was estimated at $0.7 \%$ (0.3-4.8) among healthy children in industrialized countries, and at $2.1 \%$ (1.6-2.2) among children born in low income settings, which is consistent with results obtained in our study (case fatality rate: $1.9 \%){ }^{33}$

Lastly, intrafamilial transmission of RSV described here gains significance because it reaches up to $46 \%$ of transmission among household members and a $27 \%$ incidence of secondary cases. ${ }^{1}$ This is related to our study finding that almost half of patients referred to have been in contact with household members who were acutely-ill or in close contact with these individuals.

Several vaccines have been introduced in the national immunization schedule to reduce ALRTIs burden, such asBordetella pertussis (included in the triple bacterial vaccine, the pentavalent or hexavalent vaccines), influenza and Streptococcus pneumoniae. These vaccines have had a remarkable impact, although immunization coverage still needs to be adjusted in different jurisdictions and departments.Unfortunately, a vaccine against RSV is still to be developed. At present, there are many lines of research that, if successful, would allow to administer the vaccine even during pregnancy, and thus prevent infections from occurring at a younger age. ${ }^{18}$

In accordance to what has been described here, RSV could be referred to as one of the most clinically relevant viral agents in pediatrics.In the past decade, the most significant advance made in RSV prevention has been the development of palivizumab, a humanized monoclonal antibody that binds RSV F protein and prevents the adherence of the virus to the basal membrane of the respiratory epithelium. Palivizumab is exclusively indicated for preterm infants, infants younger than 2 years old with symptomatic bronchopulmonary dysplasia and/or congenital heart diseases, who account for the population at a high risk of suffering a severe form of these conditions, including death, due to RSV infection compared to infants who do not have such a history. The relevance of its use has been clearly demonstrated in this study in relation to the risk observed in patients with these underlying conditions. ${ }^{1,34}$

Undoubtedly, the impact of RSV on the health system and the general population is greatly significant. Knowing these data will allow to adjust patient diagnostic and follow-up patterns and health policies to be implemented.It is essential to facilitate patient referral strategies so that patients are transferred and seen at tertiary care facilities, thereby reducing morbidity and mortality of the most vulnerable patients while an effective vaccine is developed.

\section{CONCLUSIONS}

In our study, RSV was the predominant agent in every year of the study period, with a seasonal epidemic pattern (May through July). RSV was associated with infants younger than 3 months old with bronchiolitis and hypoxemia at the time of hospital admission. 


\section{Acknowledgments}

We would like to thank the Unit of Virology and the staff of Hospital de Niños Ricardo Gutiérrez for their generous help.

\section{REFERENCES}

1. Sociedad Argentina de Pediatría. Comité de Infectología Pediátrica. Libro Azul de Infectología Pediátrica. 4.ta ed. Buenos Aires: SAP, 2012;413-7.

2. American Academy of Pediatrics. Respiratory Syncytial Virus. En Pickering LK, ed. Red Book: 2012 Report of the Committee on Infectious Diseases. 29th ed. Elk Grove Village, IL: American Academy of Pediatrics; 2012: 609-18.

3. UN Inter-agency Group for Child Mortality Estimation. Level \& Trends in Child Mortality. Report 2013. New York, 2013. [Consulta: 5 de junio de 2014]. Disponible en: http:/ / www.childmortality.org/files_v16/download/ UNICEF $\% 202013 \% 20 I G M E \% 20$ child $\% 20$ mortality $\% 20$ Report_Final.pdf

4. Secretaría de Políticas, Regulación e Institutos. Dirección de Estadísticas e Información de Salud. Estadísticas vitales. Información básica año 2012. Buenos Aires: Ministerio de Salud de la Nación Argentina, 2013. Serie 5 - Número 56.

5. Comité de infecciones respiratorias de la Sociedad Latinoamericana de Infectología Pediátrica. Consenso de la Sociedad Latinoamericana de Infectología Pediátrica sobre neumonía adquirida en la comunidad. Rev Enferm Infecc Pediatr 2010;24(94):1-23.

6. Portillo C, Cruz J. Implementación del método rápido de diagnóstico de virus por inmunofluorescencia en niños hospitalizados por infecciones respiratorias agudas. Arch Argent Pediatr 2000;98(2):99-102.

7. Nair H, Nokes DJ, Gessner BD, Dherani M, et al. Global burden of acute lower respiratory infections due to respiratory syncytial virus in young children: a systematic review and meta-analysis. Lancet 2010;375(9725):1545-55.

8. Griffin MR, Walker FJ, Iwane MK, Weinberg GA, et al. Epidemiology of respiratory infections in young children: insights from the new vaccine surveillance network. Pediatr Infect Dis J 2004;23(11 Suppl):S188-92.

9. Sadeghi C, Aebi C, Gorgievski-Hrisoho M, Mühlemann $\mathrm{K}$, et al. Twelve years' detection of respiratory viruses by immunofluorescence in hospitalised children: impact of the introduction of a new respiratory picornavirus assay. BMC Infect Dis 2011;11:41.

10. Jokela P, Piiparinen H, Luiro K, Lappalainen M. Detection of human metapneumovirus and respiratory syncytial virus by duplex real-time RT-PCR assay in comparison with direct fluorescent assay. Clin Microbiol Infect 2010;16(10):156873.

11. Hall CB, McCarthy CA. Respiratory Syncytial Virus. En Mandell GL, Bennett JE, Dolin R, eds. Principles and Practices of Infectious Diseases 4th ed. New York, USA: Churchill Livingstone; 1995: 1501-18.

12. Ferrero FC, González Pena H, Ossorio MF, Grenoville M. Consenso sobre infecciones respiratorias agudas bajas en menores de 2 años. Arch Argent Pediatr 1996;94(4):274-88.

13. Hall CB, Weinberg GA, Iwane MK, Blumkin AK, et al. The burden of respiratory syncytial virus infection in young children. N Engl J Med 2009;360(6):588-98.

14. Hall CB. Respiratory syncytial virus and parainfluenza virus. N Engl J Med 2001;344(25):1917-28.

15. Prendergast $C$, Papenburg J. Rapid antigen-based testing for respiratory syncytial virus: moving diagnostics from bench to bedside? Future Microbiol 2013;8(4):435-44.
16. Korppi M, Kotaniemi-Syrjänen A, Waris M, Vainionpää R, Reijonen TM. Rhinovirus-associated wheezing in infancy: comparison with respiratory syncytial virus bronchiolitis. Pediatr Infect Dis J 2004;23(11):995-9.

17. Jartti T, Lehtinen P, Vuorinen T, Osterback R, et al. Respiratory picornaviruses and respiratory syncytial virus as causative agents of acute expiratory wheezing in children. Emerg Infect Dis 2004;10(6):1095-101.

18. Anderson LJ. Respiratory syncytial virus vaccine development. Semin Immunol 2013;25(2):160-71.

19. Trento A, Galiano M, Videla C, Carballal G, et al. Major changes in the $G$ protein of human respiratory syncytial virus isolates introduced by a duplication of 60 nucleotides. J Gen Virol 2003;84(Pt 11):3115-20.

20. Trento A, Viegas M, Galiano M, Videla C, et al. Natural history of human respiratory syncytial virus inferred from phylogenetic analysis of the attachment $(G)$ glycoprotein with a 60-nucleotide duplication. J Virol 2006;80(2):975-84.

21. Glezen WP, Greenberg SB, Atmar RL, Piedra PA, et al. Impact of respiratory virus infections on persons with chronic underlying conditions. JAMA 2000;283(4):499-505.

22. Iwane MK, Edwards KM, Szilagyi PG, Walker FJ, et al. Population-based surveillance for hospitalizations associated with respiratory syncytial virus, influenza virus, and parainfluenza viruses among young children. Pediatrics 2004;113(6):1758-64.

23. Gentile A, Bakir J, Moar A, Burna V, et al. Perfil epidemiológico de las infecciones respiratorias agudas bajas en un hospital pediátrico. Arch Argent Pediatr 1996;94(1):2-9.

24. Maffey AF, Venialgo CM, Barrero PR, Fuse VA, et al. Nuevos virus respiratorios en niños de 2 meses a 3 años con sibilancias recurrentes. Arch Argent Pediatr 2008;106(4):302-9.

25. Speranza AM, Clary AL, Pereira T, Sapoznicoff L, et al. Estudio multicéntrico de infecciones respiratorias agudas bajas en niños hospitalizados menores de dos años. Arch Argent Pediatr 2003;101(5):365-73.

26. Viegas M, Barrero PR, Maffey AF, Mistchenko AS. Respiratory viruses seasonality in children under five years of age in Buenos Aires, Argentina: a five-year analysis. J Infect 2004;49(3):222-8.

27. Walton NA, Poynton MR, Gesteland PH, Maloney C, et al. Predicting the start week of respiratory syncytial virus outbreaks using real time weather variables. BMC Med Inform Decis Mak 2010;10:68.

28. Shay DK, Holman RC, Newman RD, Liu LL, et al. Bronchiolitis-associated hospitalizations among US children, 1980--1996. JAMA 1999;282(15):1440-6.

29. Lowther SA, Shay DK, Holman RC, Clarke MJ, et al. Bronchiolitis-associated hospitalizations among American Indian and Alaska Native children. Pediatr Infect Dis J 2000;19(1):11-7.

30. Viegas M. Epidemiología molecular del virus sincicial respiratorio en pacientes pediátricos en un período de seis años. Acta Bioquím Clín Latinoam 2011;45(1):3-45.

31. Heikkinen T, Waris M, Ruuskanen O, Putto-Laurila A, et al. Incidence of acute otitis media associated with group A and B respiratory syncytial virus infections. Acta Paediatr 1995;84(4):419-23.

32. Corbeel L. What is new in otitis media? Eur J Pediatr 2007;166(6):511-9.

33. Giubergia V, Martinchuk G, Moreno N, Colombres G, et al. Gravedad de la infección por virus sincicial respiratorio en pacientes con factores de riesgo y sin ellos. Arch Argent Pediatr 2004;102(5):330-4.

34. ComitédeEstudios Fetoneonatales (CEFEN). Actualización de las recomendaciones sobre el uso de palivizumab. Arch Argent Pediatr 2007;105(1):67-70. 